ppi $201502 Z U 4645$

Esta publicación científica en formato digital es continuidad de la revista impresa ISSN-Versión Impresa 0798-1406 / ISSN-Versión on line 2542-3185Depósito legal pp $197402 Z$ U34

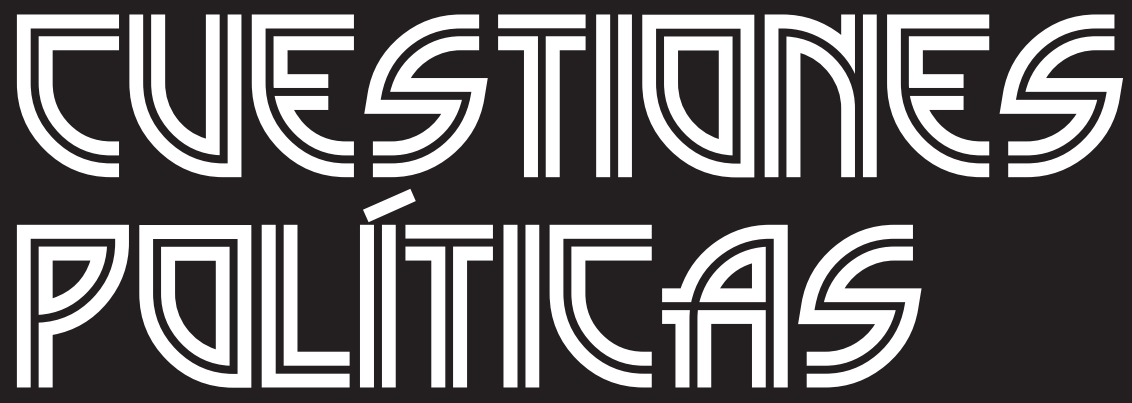

Instituto de Estudios Políticos y Derecho Público "Dr. Humberto J. La Roche" de la Facultad de Ciencias Jurídicas y Políticas de la Universidad del Zulia Maracaibo, Venezuela
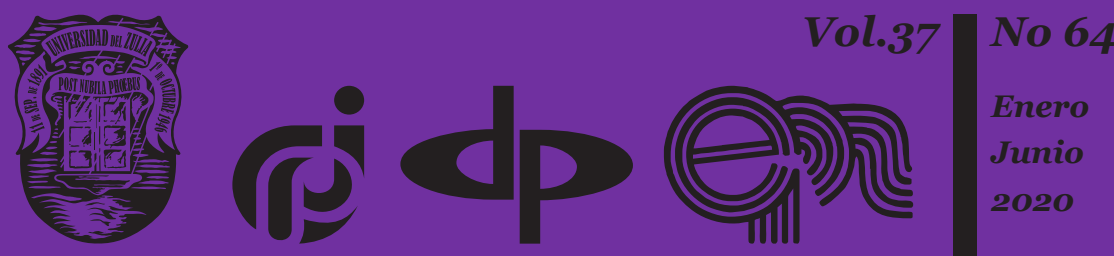


\title{
Rutas de exilio entre Argentina y Venezuela, 1974-1980: circulaciones, tránsitos y re-exilios en el contexto regional *
}

\author{
Mario Ayala **
}

\section{Resumen}

Este artículo tiene como objetivo analizar las diversas rutas de exilio entre Argentina y Venezuela a partir de las experiencias de los exiliados políticos que se refugiaron en ese país durante el tercer gobierno peronista (1973-1976) y la dictadura militar argentina (1976-1983). La metodología escogida fue el estudio cualitativo y cuantitativo de un corpus de 72 trayectorias personales sistematizados en una base de datos, cuyas fuentes fueron entrevistas orales, testimonios editados y documentación diplomática venezolana. Se reconstruyeron las rutas de exilios directas, indirectas o seriales de los exiliados que se instalaron en Venezuela entre 1974 y 1980 atendiendo sus circulaciones, tránsitos, reubicaciones y re-exilios durante la última ola represiva en el Cono Sur de América Latina. Se concluye que las rutas de exilio variaron en función de las estrategias de los sujetos exílicos en interacción con los contextos represivos del país expulsor, de la política de asilo y recepción de los países ante los cuales solicitaron protección y de las condiciones políticas regionales e internacionales en que se desplegaron los desplazamientos territoriales forzados o condicionados por razones políticas.

Palabras clave: exiliados argentinos; rutas de exilio; Venezuela; desplazamientos forzados; década del setenta.

Este trabajo es una versión ampliada y actualizada de un capítulo de nuestra investigación de doctorado (Ayala, 2017c).

** Doctor y Profesor en Historia por la Universidad de Buenos Aires. Profesor Adjunto Regular de la Universidad Nacional de Tierra del Fuego. Becario postdoctoral del Consejo Nacional de Investigaciones Científicas y Técnicas (CONICET). Dirección: Walanika 25o, Piso $3^{\circ}$, Oficina N. ${ }^{\circ} 22$-CP 9410 - Ushuaia, Provincia de Tierra del Fuego, Antártida e Islas del Atlántico Sur, Patagonia Austral - Argentina. Email: mhayala@untdf.edu.ar. 

Mario Ayala
Rutas de exilio entre Argentina y Venezuela, 1974-1980: circulaciones, tránsitos y re-exilios en el

\title{
Exile routes between Argentina and Venezuela, 1974- 1980: circulations, transits and re-exiles in the regional context
}

\begin{abstract}
This article aims to analyze the various routes of exile between Argentina and Venezuela based on the experiences of political exiles who took refuge in that country during the third Peronist government (1973-1976) and the Argentine military dictatorship (1976-1983). The chosen methodology was the qualitative and quantitative study of a corpus of 72 personal trajectories systematized in a database, the sources of which were oral interviews, edited testimonies, and Venezuelan diplomatic documentation. The direct, indirect or serial exile routes of the exiles that settled in Venezuela between 1974 and 1980 were reconstructed, attending to their movements, transits, relocations and re-exiles during the last repressive wave in the Southern Cone of Latin America. It is concluded that the routes of exile varied according to the strategies of the exile subjects in interaction with the repressive contexts of the expelling country, the asylum and reception policy of the countries before which they requested protection and the regional and international political conditions. in which forced or conditioned territorial displacements for political reasons were deployed.
\end{abstract}

Keywords: Argentine exiles; exile routes; Venezuela; forced displacement; seventies.

\section{Introducción}

En Argentina el 24 de marzo de 1976 un golpe militar derrocó al gobierno constitucional del tercer peronismo (1973-1976) e instauró una dictadura de Seguridad Nacional (1976-1983), en consonancia con las que se emplazaron en la región desde el golpe de 1964 en Brasil. Los años previos a esta ruptura institucional se caracterización por una profunda crisis política y económica y la implementación de políticas represivas estatales y paraestatales contra el proceso de radicalización política y los movimientos sociales y políticos movilizados, ya fueran estos contestatarios, rebeldes y/o de intenciones revolucionarias (Franco, 2012).

El modelo represivo de la dictadura militar se caracterizó por el uso masivo de los secuestros y detenciones clandestinas, las torturas y las desapariciones forzadas de personas con el objetivo de aniquilar materialmente toda oposición como parte de un proyecto político de reorganización de las relaciones sociales (Slatman y Serra Padrós, en: 
Jensen y Lastra, 2014). De modo que el régimen represivo inaugurado en marzo de 1976 tuvo una estrecha articulación y continuidad con las prácticas represivas del período previo, que habilitan a pensar el período 1973-1983 como parte de políticas de largo plazo en un ciclo de violencia estatal que llega hasta el golpe de Estado de 1955 (Franco, 2012).

Una de las consecuencias de este ciclo de violencia estatal de la década del setenta fue que el exilio se transformó en un fenómeno masivo de exclusión política y epílogo de otras prácticas represivas. Entre 1974 y 1983 , la persecución, el encarcelamiento, el asesinato y la desaparición forzada, el despido de empleos, la censura y, en general, la intensificación del terror contra miles de cuadros inferiores y medios de la militancia profesional, estudiantil, intelectual, sindical y política de izquierdas y sus familiares, amigos y compañeros de trabajo, convirtieron a la fuga del territorio nacional en la única alternativa para ponerse a salvo (Jensen, 2007).

Las salidas forzadas $\mathrm{y} / \mathrm{o}$ condicionadas del país sucedieron fundamentalmente en dos coyunturas. El primer momento se registró entre fines de 1973 y marzo de 1976 como consecuencia de la represión estatal y paraestatal bajo el tercer gobierno peronista. Las salidas y escapes al exterior fueron el resultado de violencia política desatada por bandas paramilitares de ultraderecha como la Alianza Anticomunista Argentina (Triple A), o de la necesidad de recuperar la libertad cambiando la prisión política por el destierro mediante la solicitud del derecho constitucional de opción que permitía "elegir" entre la cárcel o la expulsión con imposibilidad de retornar hasta la finalización del Estado de sitio (noviembre 1974-diciembre de 1983).

El segundo momento de salidas al exterior se activó con el golpe militar de 1976 extendiéndose a lo largo de toda la dictadura. Como ha demostrado la historiadora Silvina Jensen (2007), el mayor número de exilios se registró entre 1976-1978 durante la etapa de represión más dura y sistemática dirigida y ejecutada por los militares. Los años 1979 y 1980 fueron el último momento de salidas numéricamente significativas -no obstante, hubo exilios hasta 1983-, efectuadas por sobrevivientes de centros clandestinos de detención y tortura, los presos que accedieron al derecho de opción, o aquellos que sobrevivieron en la clandestinidad o en el exilio interno antes de salir de país. En ambas coyunturas represivas, la práctica del destierro y el exilio fueron el epílogo de prácticas represivas previas (Jensen, 2007).

De modo general, se puede afirmar que durante este último exilio argentino los escapes se concretaron mayormente como salidas del país bajo la condición de turistas, viajes de trabajo, como huidas clandestinas a países limítrofes, o desde las cárceles recurriendo a visas de salida y siendo recibidos como refugiados o asilados, siendo muy bajo el nivel de asilos en embajadas (Yankelevich, 2010). Estas salidas fueron sin duda una forma de escapar a la represión para resguardar la vida y la libertad y adoptaron 
Mario Ayala

Rutas de exilio entre Argentina y Venezuela, 1974-1980: circulaciones, tránsitos y re-exilios en el

la forma de un proceso colectivo que no tuvo un carácter organizado, pues ninguna fuerza política dio la orden de emprenderlo, sino que más bien se desarrolló a partir de una sumatoria de acciones de carácter individual o familiar a lo largo de varios años, principalmente en los primeros de la dictadura (Yankelevich, en Lida et al, 2008; Jensen, 2007). Las vías al exilio más transitadas fueron el aeropuerto internacional de Ezeiza en Buenos Aires y las fronteras terrestres con países limítrofes, mayormente con Brasil y Uruguay, y en menor medida con Paraguay o Bolivia.

A nivel regional, desde mediados de los setenta las dictaduras de Seguridad Nacional del Cono Sur (Brasil, Argentina, Chile, Uruguay) incrementaron su cooperación y coordinación represiva con la intención de vigilar, perseguir, capturar o asesinar a militantes políticos más allá sus fronteras nacionales, evitando -además- su establecimiento en países limítrofes y recortando sus posibilidades de articular desde ellos actividades de resistencia y lucha. De modo que para ponerse a salvo de esta ola represiva transnacional la mayoría de estos perseguidos y desterrados políticos fueron obligados a instalarse en países no limítrofes o de otros continentes (Ayala, 2017c).

En el caso de los que escapaban de la represión en Argentina, las circulaciones, tránsitos y re-exilios en el ámbito transregional fueron condicionados significativamente por cambios en la situación interna de dos dictaduras de la región. En Perú, con el desplazamiento de Juan Velasco Alvarado y su reemplazo por Francisco Morales Bermúdez, la dictadura militar nacionalista reformista que gobernaba ese país desde 1968 ingresó en una fase derechista, anticomunista y represiva desde agosto de 1975, abandonando su política de protección y acogida de perseguidos de la región, sumándose a la coordinación represiva regional y obligando a re-exiliarse en terceros países a buena parte de la colonia de exiliados argentinos.

Por su parte en Brasil, la dictadura militar que gobernaba desde 1964 inició un proceso de distensión política bajo el comando del dictador Ernesto Geisel, que implicó cierta tolerancia al movimiento y permanencia transitoria de exiliados de la región. Quienes lograban atravesar las fronteras y esquivar los esquemas de coordinación represiva bilaterales, llegaban hasta Rio de Janeiro o San Paulo a la espera de documentación y protección de terceros estados. Durante el tiempo de tránsito se ponían al amparo de organizaciones de derechos humanos y de la agencia para los refugiados y desplazados de Naciones Unidas el ACNUR -en adelante solo ACNURbuscando escapar a la siempre posible represión de los militares brasileros (Slatman y Padros, 2014; Viz Quadrat, 2007; Franco, 2006; Fernández, 2011; Jensen, 2007; Ayala, 2017c). Después del golpe de 1976, Brasil fue el país más utilizado por los exiliados argentinos como espacio de tránsito, circulación y puente hacia Europa, México o Venezuela. En definitiva, con el 
Cono Sur gobernado por dictaduras militares, los perseguidos que buscaban exiliarse en países latinoamericanos debieron buscar ser aceptados por los de gobiernos Venezuela, México, Cuba, Colombia o Costa Rica.

Desde el retorno a la democracia en 1958, Venezuela se convirtió por décadas en un lugar de atracción y recepción de exiliados de las oleadas represivas de la región. Sobre todo, por la imagen internacional de poseer un sistema político democrático estable y una prospera economía petrolera que posibilitaba la inserción relativamente fluida en el mercado de trabajo (Sznadjer y Roniger, 2013), que demandaba profesionales y técnicos con buenos salarios en dólares. Fue uno de los países latinoamericanos que debió afrontar un contingente cuantioso de solicitudes de asilo político en sus sedes diplomáticas de Brasil, Chile, Uruguay, Argentina y Bolivia en las coyunturas de los golpes de Estado y las dictaduras militares que le siguieron. Llego a ser el principal lugar de exilio en América del Sur de esta oleada de desterrados cono-sureños.

En otro trabajo (Ayala, 2017c), demostramos que, ante estas coyunturas, los gobiernos del socialdemócrata Carlos Andrés Pérez (1974-1979) y el socialcristiano Luis Herrera Campins (1979-1984) adoptaron una política de asilo restrictiva "anticomunista" que busco bloquear los ingresos de perseguidos políticos "izquierdistas" desde el Cono Sur. Entre mediados de 1974 y fines de 1983, las solicitudes de asilo diplomático y visas de ingreso a Venezuela presentadas por presos y perseguidos políticos ante su Embajada de Buenos Aires fueron tratadas con este criterio restrictivo, que se combinó con la aplicación de una política de inmigración selectiva que priorizada el ingreso de profesionales y técnicos que demandaba el mercado de trabajo (Pellegrino, 1989).

A pesar de esta política de asilo restrictiva e inmigración selectiva, el análisis de las fuentes gubernamentales venezolanas y los testimonios de exiliados mostraron que estas políticas receptoras dificultaron las salidas de perseguidos y presos políticos, pero no evitaron que cientos de ellos ingresaran al país en calidad de trabajadores o como turistas desde Argentina, a partir terceros países, o de forma ilegal a través de la extensa frontera colombo-venezolana, gracias a redes políticas, familiares y profesionales. Las investigaciones sobre los principales países del exilio de argentino de la década del setenta han examinado las rutas e itinerarios de las salidas forzadas y los desplazamientos territoriales por razones políticas entre el país de origen y el país de acogida para los casos de Israel, Cataluña, Francia, México y Porto Alegre (Sznadjer y Roniger, en: Yankelevich, 2004; Jensen, 2007; Franco, 2008; Yankelevich, 2010; Fernández, 2011).

En lo concreto, este artículo tiene como objetivo reconstruir y analizar las rutas de exilio entre Argentina y Venezuela a partir de las experiencias de exiliados que, tras circulaciones, tránsitos, re-exilios y reubicaciones en el espacio regional e internacional, se refugiaron en ese país durante el 
Mario Ayala

Rutas de exilio entre Argentina y Venezuela, 1974-1980: circulaciones, tránsitos y re-exilios en el contexto regional

tercer gobierno peronista y la dictadura militar. La metodología escogida fue el estudio cualitativo y cuantitativo de un corpus de 72 trayectorias personales sistematizados en una base de datos ${ }^{3}$, cuyas fuentes fueron, entrevistas realizadas por el autor entre 2008 y 2014, testimonios editados y documentación diplomática venezolana alojada en el Archivo Central del Ministerio de Relaciones Exteriores de Venezuela ${ }^{4}$. La identidad de las personas entrevistadas ha sido resguardada y se utilizan iniciales, salvo en los casos que dieron su autorizaron. Por lo demás, se reconstruyen las rutas de exilios directas, indirectas o seriales de los exiliados que se instalaron en Venezuela entre 1974 y 1980 atendiendo sus circulaciones, tránsitos, reubicaciones y re-exilios durante la última ola represiva en el Cono Sur de América Latina.

El texto se organiza en tres partes y un balance final. En la primera, se presenta el marco analítico del trabajo y, en base al estudio de las fuentes, se proponen tres tipos de rutas o itinerarios de desplazamiento territorial, a los que planteamos identificar como rutas de exilio directas, rutas de exilio indirectas y rutas de exilio serial. En la segunda parte, se analizan las rutas de exilio observadas durante el tercer gobierno peronista y, en la tercera, aquellas que trazan las experiencias de exiliados que llegaron a Venezuela durante la dictadura militar para arribar, en el último apartado, a las conclusiones o reflexiones finales del estudio.

\section{El exilio y sus rutas}

El marco analítico de la investigación se apoya en el estudio de (Mario Sznadjer y Luis Roniger, 2013) sobre la práctica del destierro y exilio en América Latina desde una perspectiva histórica continental, comparativa y transnacional entre el periodo colonial y fines siglo XX. En particular se emplearon de esta obra dos cuestiones que consideramos útiles para el objetivo de este artículo. La primera de ellas es su definición del exilio político como un mecanismo de exclusión y dislocamiento institucionalizado en la política latinoamericana cuyo objetivo es excluir de la comunidad política y de las esferas públicas a ciudadanos y residentes considerados opositores por el régimen de turno (Sznadjer y Roniger, 2013).

3 La Base de Datos compiló información de 16 variables extraídas de 72 trayectorias personales que fueron analizadas en profundidad, producto de entrevistas personales realizadas ad hoc o publicadas como testimonios. Estas variables fueron: nombre, edad, lugar de origen, militancia (o no), fecha de salida, actividad laboral-profesional, forma de salida (asilo, escape, derecho opción, como turista o emigrante), países de tránsito/exilio, fecha de llegada Venezuela, ciudad o Estado de radicación, grupo familiar, inserción laboral, participación en organizaciones de exiliados, partidos políticos u organizaciones de derechos humanos, retorno/no retorno.

4 Disponible en el Fondo Archivo Bilateral con Argentina (ABA) del Archivo Central del Ministerio de Relaciones Exteriores de Venezuela (ACMREV), Caracas, Venezuela, (en adelante ACMREV-ABA), en particular durante el período 1973-1984. 
Tal como indicó (Jensen, 2015) la ventaja y utilidad de esta definición operativa del exilio como una reubicación forzada permite extrapolar analíticamente a los exiliados del universo de otros desplazamientos humanos internacionales voluntarios como: los migrantes, los cosmopolitas, viajeros o turistas, subrayando su triple dimensión punitivoterritorial, político-opositora y sostenida en un proyecto de retorno. Desde esta perspectiva, mirando el problema desde la experiencia histórica del último ciclo de dictaduras en el Cono Sur, la autora subraya además que los destierros y exilios deben pensarse como fenómenos históricos cambiantes que pueden adoptar la forma de exclusiones institucionalizadas o de medidas arbitrarias de hecho, como huidas o fugas producto del miedo a ser víctima de cárcel o asesinato (Jensen, 2015).

La segunda cuestión que emplea de la obra de (Sznadjer y Roniger, 2013) es su perspectiva de análisis sobre los factores más importantes que influyeron para seleccionar los lugares de exilio en la región durante el siglo XX, en la cual demuestran que el México postrevolucionario y la Venezuela redemocratizada posterior a 1958 (junto con Cuba después de 1959) jugaron un rol importante como lugares de recepción, atracción, reunión y proyección de los exiliados latinoamericanos. Los autores abordan el fenómeno a partir de una serie de factores interactuantes que tienen en cuenta las lógicas de los Estados y regímenes productores o receptores de exilios, así como las experiencias particulares de los sujetos víctimas de desplazamientos forzados o condicionados por la violencia política y la represión.

Partiendo de que cuando más severa es la persecución y más acuciante la necesidad de salir del país para salvar la vida, menos serán las opciones en la elección de un país de asilo o refugio, circunstancia que muestran que las decisiones que llevan a la elección de un lugar de exilio involucran la interacción entre factores tan diversos como: las circunstancias expulsoras; los antecedentes personales, recursos, capitales, redes y contactos del perseguido en el extranjero y: "La receptividad y el atractivo de los países anfitriones en términos de distancia, clima, lengua y apoyo institucional, como de oportunidades económicas, profesionales y educativas" (Sznadjer y Roniger, 2013: 122).

Otro componente importante en la ecuación es el apoyo (o la falta de él) que reciban los exiliados tanto de organizaciones transnacionales, redes de solidaridad, diversas ONG, como de las comunidades de exiliados y diásporas de connacionales, que son claves para facilitar, por una parte, su ingreso e integración en el lugar de exilio y, por otra, la continuidad de su proyecto de vida y actividad política. De cualquier modo, todo indica que todos estos factores interactúan entre ellos y varían en cada caso. Ahora bien, ¿qué matices cobra este proceso para el caso de los exiliados que durante la década del setenta partieron de Argentina con destino o llegaron, finalmente, a Venezuela tras diversos itinerarios y rutas de exilio? 


\footnotetext{
Mario Ayala

Rutas de exilio entre Argentina y Venezuela, 1974-1980: circulaciones, tránsitos y re-exilios en el contexto regional
}

El examen de las 72 trayectorias que constituyen la base central de esta investigación indicó que la mayoría de los perseguidos políticos argentinos que llegaron a Venezuela lo hicieron a través de tres tipos de rutas o itinerarios de desplazamiento territorial forzado, compulsivo o condicionado por razones políticas, que proponemos definir de forma operativa como: rutas de exilio directas, rutas de exilio indirectas y rutas de exilio serial. Las rutas de exilio directas fueron aquellas en las que el itinerario del desplazamiento territorial se concretó mediante un viaje directo entre el país de origen y el país de destino; las rutas de exilio indirectas, se refieren a aquellas en las que el itinerario del desplazamiento territorial implicó situaciones de tránsito en terceros países por tiempos variables, o fueron el producto de re-emigraciones o reubicaciones en el exilio por motivos políticos, económicos, familiares y/o culturales; mientras que las rutas de exilio serial, serian todas aquellas en las que el itinerario del desplazamiento territorial implicó situaciones de re-exilio desde terceros países donde se impusieron restricciones a la libertad de acción de los exiliados y/o se puso en peligro su protección personal y jurídica. Esta última noción retoma la definición de "exilio serial” de Sznadjer y Roniger, que lo definen como:

...el desplazamiento subsecuente, y en ocasiones recurrente, de un sitio de exilio a otro, conforme los países en los que se asientan los individuos desplazados restringen su libertad de acción. Tales restricciones con frecuencia se deben a las políticas de asilo, a presiones que ejercen los países de origen, o a que algún país anfitrión entre a una fase de represión política y dictadura (Sznadjer y Roniger, 2013: 226).

En los apartados que siguen se reconstruyen las rutas de exilios directas, indirectas o seriales de los exiliados que se instalaron en Venezuela y se propone una discusión más amplia sobre las lógicas políticas y tramas represivas regionales que condicionan estos desplazamientos forzados y dieron sentido a las circulaciones, tránsitos, reubicaciones y re-exilios durante la última ola represiva en el Cono Sur de América Latina.

\section{Las rutas de exilio antes del golpe de Estado (1974-1976)}

Sobre el total de 72 trayectorias personales estudiadas, encontramos que 28 llegaron a Venezuela durante el tercer gobierno peronista. La primera comprobación que arroja su estudio es que 19 de ellas (el 68 \%) se trasladaron directamente a Caracas por vía aérea, configurando casos de rutas de exilio directas. Se trató centralmente de presos políticos que 
hicieron uso del derecho de opción que reconoce la Constitución Nacional ${ }^{5}$ (cambiar el encarcelamiento por el exilio) y de personas que huían de otras modalidades represivas, que salieron de Argentina con visas venezolanas o como asilados diplomáticos y que ingresaron a Venezuela con visas de turista o de trabajo, la mayoría con pasaportes argentinos gestionados con dificultades y, en contados casos, con pasaportes de emergencia ${ }^{6}$ otorgados por la cancillería venezolana.

La segunda comprobación fue que 8 personas (el 29 \%) llegaron a Venezuela a través de diversas rutas de exilio indirectas. En primer lugar, hallamos casos que lo hicieron después de situaciones de tránsito en Colombia, Perú y Brasil. En los tres casos que salieron por vía aérea hacia Colombia (Luna, 2008; E.P. y L.M., 2014; Canal Encuentro, 2015b), la elección de esa ruta fue producto de la combinación entre la necesidad de salir urgente de las cárceles por el derecho de opción y/o el incremento del peligro de ser víctima de la represión, mezclados con la negación de visas de ingreso por la Embajada de Venezuela en Argentina (EMBAVEN-AR) (Ayala, 2017c).

Esta situación límite los impulsó a buscar salir hacia Colombia, país que les otorgó visas sin inconvenientes ni retrasos, y desde allí continuaron las gestiones para ingresar en Venezuela en las semanas siguientes: uno de ellos, mediante solicitud de visa y traslado por vía área, y los otros dos atravesando como turistas la frontera colombo-venezolana por vía terrestre. Después una estadía transitoria en Perú ingresó a Venezuela Alberto, un médico perseguido por su simpatía con la Juventud Peronista. Luego de obtener su pasaporte argentino dos días antes del golpe de Estado viajó de urgencia a Lima para ponerse a salvo y desde allí continuar gestionar el ingreso al país caribeño que había restringido el asilo diplomático y la entrega de visas para escape.

Un tercer ejemplo de rutas de exilio indirectas en la variable de tránsitos fue el recorrido de W.R, militante del Partido Revolucionario de los Trabajadores (PRT) que, en agosto de 1975, al no ser autorizada para ingresar a Venezuela, decidió salir de Argentina con destino a Curazao en un vuelo con escala en Caracas. Cuando el avión de W.R. aterrizó en Caracas, un senador del Movimiento Electoral del Pueblo (MEP) ${ }^{7}$ acompañado de

5 Según el artículo 23 de Constitución Nacional de Argentina los presos a disposición del Poder Ejecutivo Nacional durante la vigencia del Estado de sitio tienen derecho al uso del derecho de salida del país como una alternativa para resolver su situación legal. El Estado sitio se mantuvo vigente en Argentina entre el 6/11/1974 y el 28/10/1983. Luego del golpe de Estado, este derecho constitucional fue suspendido por periodos o aplicado de forma discrecional.

6 El pasaporte de emergencia era un documento emitido por el Estado venezolano que brindaba protección y reconocimiento a los apátridas y perseguidos políticos y tenía una validez variable según los casos.

7 Seguramente este senador del MEP fue Orestes De Giacomo, coordinador general del Comité Venezolano de Solidaridad con el Pueblo Argentino (CVSP), véase: (Ayala, 2014). 
Mario Ayala

Rutas de exilio entre Argentina y Venezuela, 1974-1980: circulaciones, tránsitos y re-exilios en el

un grupo de exiliados argentinos (entre los que se encontraba su marido, un ex preso opcionado) realizó gestiones in situ ante el Departamento de Inmigración y Extranjería (DIEX) del Ministerio de Interiores (MI) para que fuera declarada asilada territorial. La estrategia funcionó y se permitió su ingreso y permanencia en Venezuela (W.R., 2014).

Entre las rutas indirectas hallamos un caso de reubicación en el exilio de México a Venezuela por motivos socioeconómicos: una pareja de académicos (Vilanova y Torre, 2013; 2014) de la Universidad Nacional del Sur que, después de ser cesanteados y temer por su vida, salieron a México en búsqueda de oportunidades para insertarse laboralmente y sobrevivir un tiempo hasta que cambiara la situación política y represiva. Pero pocos meses después de llegar a ese país se trasladaron a Venezuela, luego de conseguir un contrato de trabajo en la Universidad de Los Andes, en el estado Mérida.

Dentro de los exiliados que llegaron a Venezuela antes del golpe de Estado de marzo de 1976 también encontramos un caso (el 3\%) de ruta de exilio serial después de un primer exilio en Perú. Se trató del actor Norman Bridski (Bridsky en: Parcero, 1985; Canal Encuentro, 2015a), afín a la organización político-militar peronista Montoneros, que en 1974 escapó de Buenos Aires hacia el Perú gobernado por el general Velasco Alvarado, huyendo de las amenazas del escuadrón de la muerte Alianza Anticomunista Argentina. Un tiempo después de ingresar a ese país, Bridski fue obligado a presentarse regularmente en dependencias policiales peruanas para controles. Frente al hostigamiento policial, que se sumaba a una vivencia de dislocamiento y depresión por el exilio, decidió trasladarse a Caracas junto a su familia ocho meses después de su llegada a Perú, con la intención de buscar trabajo en su profesión y residir en un país con un ambiente político democrático y con un espacio cultural más amplio. Esta nueva migración forzada puede ser considerada analíticamente como un re-exilio o exilio serial.

\section{TABLA 1: Tendencias de las rutas de exilio entre Argentina y Venezuela, 1974-1980 $($ Total $=72)$}

\begin{tabular}{|l|c|c|c|c|c|c|}
\hline $\begin{array}{l}\text { Tipo de ruta } \\
\text { de exilio }\end{array}$ & $\begin{array}{c}\text { Tercer gobierno } \\
\text { peronista }\end{array}$ & Porcentaje & $\begin{array}{c}\text { Dictadura } \\
\text { militar }\end{array}$ & Porcentaje & Total & Porcentaje \\
\hline $\begin{array}{l}\text { Rutas de exilio } \\
\text { directas }\end{array}$ & 19 & $68 \%$ & 18 & $40 \%$ & 37 & $51 \%$ \\
\hline $\begin{array}{l}\text { Rutas de exilio } \\
\text { indirectas }\end{array}$ & 8 & $29 \%$ & 16 & $36 \%$ & 24 & $33 \%$ \\
\hline $\begin{array}{l}\text { Rutas de exilio } \\
\text { serial }\end{array}$ & 1 & $3 \%$ & 10 & $22 \%$ & 11 & $15 \%$ \\
\hline Total, casos: & 28 & $100 \%$ & 44 & $100 \%$ & 72 & $100 \%$ \\
\hline
\end{tabular}

Fuente: Elaboración propia. 


\section{Las rutas de exilio después del golpe de Estado}

Dentro de las 72 trayectorias personales analizadas se comprobó que 44 de ellas llegaron y se instalaron en Venezuela después del golpe de Estado del 24 de marzo de 1976. Las rutas de exilio que trazan estas experiencias de destierro revelan que los itinerarios de desplazamiento forzado fuera del territorio argentino se modificaron sustancialmente en comparación con los casos que llegaron durante el tercer gobierno peronista.

Las rutas de exilio directas sumaron 18 casos y constituyeron la mayoría (el $40 \%$ ). Se trató de asilados, perseguidos y sobrevivientes de centros clandestinos de detención (CCD) de prisioneros políticos que llegaron a Venezuela desde el aeropuerto internacional de Ezeiza, ${ }^{8}$ algunos con pasaportes argentinos legales, otros con pasaportes de emergencia venezolanos, e incluso con pasaportes venezolanos falsificados. A continuación, mostramos sólo una selección de casos que expresan las diversas situaciones y circunstancias. Existieron muchos otros. Entre los que recibieron protección diplomática para su salida fue el del diputado del partido radical Adolfo Gass y cinco miembros de su familia (Gass, 2009). Fueron recibidos y asilados informalmente en la EMBAVEN-AR a fines de junio de 1976 luego de haber sufrido persecución, amenazas y la colocación de explosivos en su domicilio debido a la militancia montonera de uno de sus hijos.

Diez días después, el grupo familiar fue conducido hasta el aeropuerto de Ezeiza en medio de un fuerte dispositivo de control e intimidación policial hasta que abordaron un vuelo hacia Caracas. Una vez en la aeronave, el piloto venezolano se acercó a Gass y le aconsejó no bajar del avión en la escala en Brasil: "Para evitar cualquier incidente con las autoridades brasileras", una forma eufemística de sugerirle que podía correr peligro de detención' 9 .

Los casos de presos políticos y sobrevivientes de desapariciones forzadas fueron varios y vale la pena detenerse en algunos. Un caso público fue el del senador del partido radical Hipólito Solari Yrigoyen, expulsado el 17 de mayo de 1977 con la condición de no regresar ${ }^{10}$. Su extrañamiento -como lo denominó el Encargado de Negocios venezolano en Buenos Aires- fue una respuesta de la dictadura a la presión internacional por su liberación y, en concreto, a las gestiones que en octubre de 1976 había iniciado el presidente venezolano Carlos Andrés Pérez, aprovechando el proceso de acercamiento

8 En esa época el principal aeropuerto internacional de Argentina, situado a 40 kilómetros de la Ciudad de Buenos Aires.

9 La familia Gass llegó a Venezuela el 9 julio de 1976. Allí Gass debió gestionar documentación y registrarse como asilado político, razón por la cual debió concurrir a una entrevista en la DISIP. Ver también ACMREV-ABA. AP.319. Embajador Santander a DGPI. 6 de julio de 1976.

10 ACMREV-ABA. DG-1718. 21 de octubre de 1976; AP-150. 11 de mayo de 1977 y AP-156. 17 de mayo de 1977. 
Mario Ayala

Rutas de exilio entre Argentina y Venezuela, 1974-1980: circulaciones, tránsitos y re-exilios en el contexto regional

entre Venezuela y Argentina (Ayala, 2017c).

Otro caso notable de rutas de exilio directas durante la última dictadura militar fue el de un grupo de siete militantes de Montoneros (Daleo, 2008; Cubas y Quiroga, 2009; Actis, 2012) que sobrevivieron al centro clandestino de detención que funcionó en la Escuela de Mecánica de la Armada Argentina (ESMA). Fueron liberados en el Aeropuerto Internacional de Ezeiza entre enero y julio de 1979 y exiliados a Venezuela. También hallamos el caso de D.M, que salió vía Ezeiza en marzo de 1979 con documentación venezolana falsificada que le enviaron desde Caracas. D.M. y su esposo eran militantes de Montoneros. Entre 1976 y 1978 habían huido de la ciudad de La Plata (Provincia de Buenos Aires) y vivido primero en San Francisco (Provincia de Córdoba) y luego en Mar del Plata (Provincia de Buenos Aires), de forma clandestina con identidades falsas, hasta que a fines de 1978 decidieron salir del país de forma clandestina en el contexto de relativa reducción de la represión. Como su esposo era hijo de ciudadanos venezolanos, consiguió documentación legal de ese país, pero D.M., al no tener pasaporte argentino y ser buscada por los militares debió esperar a que sus familiares le enviaran desde Venezuela documentación falsificada para ella y su hija (D.M., 2010).

Finalmente, entre los casos que intentaron salir de forma directa a Venezuela a través del aeropuerto de Ezeiza, vale la pena mencionar el escape frustrado seguido de secuestro y desaparición forzada de Nélida Sosa de Forti ${ }^{11}$. Miembro laico de la cristiana Hermandad de Hermanos de Foucauld. Sosa de Forti y sus cinco hijos fueron secuestrados mientras se encontraban a bordo de un avión de Aerolíneas Argentinas con destino a Caracas a inicios de 1977. Tras el golpe de marzo de 1976, la familia había abandonado la provincia de Tucumán por temor y se radicó por un tiempo en Córdoba. Producto de la persecución de los militares, Nélida y sus hijos se trasladaron de Córdoba a Buenos Aires y el 18 febrero de 1977 abordaron un vuelo que los llevaría a Caracas. Pero el avión fue detenido y abordado por un grupo de represores que los capturó y secuestró. Una semana más tarde, liberaron a sus hijos. Nélida, en cambio, continúa desaparecida. Este caso de salida fallida por vía área quedó grabado en la memoria de los exiliados argentinos en Venezuela y fue un hecho que hizo que muchos perseguidos cambiaran su vía de escape, alertados por las redes de exiliados.

En cuanto a las rutas de exilio indirectas durante la dictadura, registramos 16 casos (el 36\%). Las trayectorias muestran que estas rutas se modificaron en comparación con las observadas durante el tercer gobierno peronista: hubo mayor cantidad de tránsitos legales e ilegales a través de Brasil y en

11 La historia de Nélida Sosa de Forti apareció en los relatos de varios entrevistados, como (B.A., 2008) quien acompaño a la familia en los días previos al momento de la salida y en los del sacerdote italiano (Alfonso Naldi, 2009), en aquel tiempo radicado en Venezuela y responsable de viajar a la Argentina a gestionar la aparición de la familia, regresando a Caracas con los cinco niños que habían sido liberados a una semana del secuestro. 
menor medida por Uruguay, más usos de las escalas en Venezuela de vuelos hacia otros destinos, e incluso personas que se trasladaron entre Argentina y Venezuela por vía terrestre. También se observaron reubicaciones en el exilio desde países europeos.

Un primer tipo de ruta de exilio indirecta posterior al golpe de Estado fue la que recorrieron ocho perseguidos que llegaron a Venezuela desde Brasil. Permanecieron en ese país en situación de tránsito un tiempo variable -de semanas a varios meses-, escapando del peligro de ser secuestrados o luego de conseguir el derecho de opción, con el objetivo de acceder a documentación internacional y/o a visas de ingreso a Venezuela. Cinco de ellos huyeron por vías terrestres fingiéndose turistas o lugareños y cruzaron la frontera por los pasos fronterizos de Puerto Iguazú-Foz do Iguazú y Paso de los Libres-Uruguaiana, mientras que otros dos fueron una pareja de presos opcionados que salieron por vía área a Rio de Janeiro con la intención de continuar gestiones de visas para ingreso a Venezuela.

En todos los casos subsistieron en Río de Janeiro entre dos semanas y seis meses a la espera de visas y pasaportes de emergencia venezolanos o de la Cruz Roja. Esta información coincide con los resultados de otras investigaciones del último exilio de argentinos, que señalaron que la ruta de salida por vía terrestre hacia Brasil fue utilizada principalmente por perseguidos que no tenían pasaportes y que, ante el peligro de ser víctimas inminentes del aparato represivo, decidían atravesar las fronteras, peligrosas pero porosas, con Brasil. Sobre todo, por los pasos de Puerto Iguazú-Foz Iguazú (Estado de Paraná) y Paso de los Libres-Uruguaiana (Estado de Rio Grande do Sul), a través de los que podían ingresar a Brasil como turistas o para realizar compras utilizando cédula o documento de identidad (Jensen, 2004; Franco, 2008; Fernández, 2011; Simões Fernandes, 2014). Estos trabajos también subrayan que Brasil fue mayormente un destino provisorio para los exiliados argentinos, si bien se registraron casos que pasaron todo su exilio allí (Fernández, 2011; Viz Quadrat, 2007).

La mayoría de los perseguidos que huían de la dictadura argentina consideraban a Brasil como un lugar "no del todo seguro" pero desde el que se podía acceder a organismos internacionales como el ACNUR aunque muchos desconocían el mecanismo del refugio y lo descubrieron buscando formas de salir de Brasil hacia un tercer país ${ }^{12}-\mathrm{o}$ a delegaciones de gobiernos extranjeros, lo que implicaba acceso a cierta protección legal, documentación internacional, visas y recursos para trasladarse hacia países seguros. Las investigaciones de Jorge Fernández sobre los exiliados argentinos en Porto Alegre, de Silvina Jensen sobre el caso de Cataluña y de Marina Franco sobre Francia, han demostrado que quienes conseguían ingresar a Brasil sin ser detenidosy/o deportados por sus fuerzas deseguridad

12 Tema destacado también por Marina Franco en su investigación sobre el caso de Francia (véase: Franco, 2006: 153-154). 
Mario Ayala

Rutas de exilio entre Argentina y Venezuela, 1974-1980: circulaciones, tránsitos y re-exilios en el

y lograban llegar hasta Rio de Janeiro u otras ciudades importantes (como Porto Alegre, Sao Paulo o Belo Horizonte) podían recibir el apoyo de redes religiosas y de solidaridad con los exiliados, como el Comitê de Defesa dos Direitos Humanos Para os Países do Cone Sul (CLAMOR), que los asistían en los aspectos prácticos y urgentes y los ponían en contacto con el ACNUR.

Él ACNUR podía concederles el estatuto de refugiado a partir del cual recibían un estipendio económico y un reconocimiento oficial de hecho ante una posible represión/deportación de la dictadura brasilera, mientras comenzaban a cabildear y esperar por documentación, visas y pasajes para países de refugio estables (Jensen, 2004; Franco, 2006; Fernández, 2011). La trayectoria de la pareja de M.B. (M.B., 2008) y R.Q. (R.Q., 2011) y su pequeña hija puede tomarse como un ejemplo representativo de este tipo de ruta de exilio indirecta. Después del golpe huyeron preventivamente del pueblo de la cuña boscosa santafesina donde vivían y trabajaban. Hasta febrero de 1977 se desplazaron por diferentes lugares del país. Viajaban con poco dinero, a lo que se sumó el embarazo de M.B. Los contactos que sus familiares tenían con la iglesia católica los conectaron con la EMBAVENAR, que les ofreció visas para salir a Venezuela. Pero M.B. y su hija no tenían pasaportes; su esposo era el único que estaba en condiciones de salir del país por vía aérea. Ante esta situación, el embajador les habría ofrecido asilo diplomático para R.Q., pero la opción creó un dilema y mucha angustia ante la posibilidad de separarse. Posteriormente, les propusieron entregarles visas y pasaportes en el Consulado de Venezuela en Rio de Janeiro. Salieron en tren hasta Puerto Iguazú e hicieron "la famosa excursión a los tres puntos de la frontera. Y en Brasil no regresamos. Nos quedamos" (M.B., 2008). Una vez que llegaron a Rio de Janeiro debieron esperar tres meses por la documentación venezolana, de la que recibieron solamente la visa y no los pasaportes de emergencia prometidos:

En Río de Janeiro encontramos que había cantidades de argentinos exiliados y tomamos contacto con el ACNUR [...] Porque la embajada [venezolana en Argentina] había mandado las visas, pero decían que no podía otorgar pasaportes [de emergencia]. Entonces ahí el ACNUR me consiguió un Laissez Passer [Documento de viaje] de la Cruz Roja. iY el 25 de mayo de 1977 llegamos a Caracas! (M.B., 2008: s/p).

Otra trayectoria significativa de tránsito por Brasil fue la de E.P. (E.P., 2014) y su novia M.H., militantes de la Juventud Peronista de La Plata, quienes entre 1975 y 1978 sobrevivieron "en la semi clandestinidad". En agosto de 1978, después de quefamiliares radicados en Venezuelagestionaran visas de ingreso que prometieron ser entregadas en su Consulado de Rio Janeiro, lograron cruzar la frontera dentro del auto de otros familiares por el Paso de los Libres (Provincia de Corrientes), sin tener que mostrar sus documentos de identidad. Sin pasaportes y en una situación de extrema vulnerabilidad, se dirigieron a Rio de Janeiro, donde decidieron solicitar acogerse al estatuto de refugiados del ACNUR. Debieron esperar seis meses 
para acceder a las visas venezolanas. E.P. afirmó que el Cónsul venezolano sólo accedió entregárselas después de que Guy Prim, responsable de la oficina del ACNUR en esa ciudad, se las solicitara personalmente para realizar la evacuación de la pareja con extrema urgencia: estaban siendo vigilados y seguidos por los servicios de inteligencia brasileros. Fue así como a inicios de 1979 lograron ingresar a Venezuela con una laissez passer emitido por la Cruz Roja, una visa de ingreso entregada por el Consulado venezolano y pasajes aéreos financiados por familiares.

Estas trayectorias de tránsito por Brasil tuvieron sus causas en el peligro de ser alcanzados por la represión, en la perspectiva o promesa de obtener documentación internacional y visas de ingreso, refugio o asilo en terceros Estados y en la porosidad de los pasos fronterizos terrestres, que volvían la maniobra arriesgada pero posible. Fue consecuencia de las modalidades represivas del país expulsor y de la política de recepción restrictiva en asilo e inmigración que junto a las condiciones de los países limítrofes en términos generales explican las vías de escape y las rutas de exilio.

Otra ruta de exilio indirecta fue la de cuatro perseguidos y sus familias, que escaparon de Argentina hacia Uruguay por vías fluviales, terrestres y aéreas en calidad de turistas. Desde allí se trasladaron hacia Venezuela o terceros países, utilizando diversas escalas para no despertar sospechas (B.A., 2008; L.V., 2008; R.F. y M.T., 2009; Affatato, 2013). La experiencia de la familia B.A. y L.V. resulta ilustrativa para exponer las cambiantes circunstancias que forzaron a los perseguidos a arriesgarse en esta ruta de escape, descartando otras posibilidades. B.A., L.V. y sus seis hijos vivían en la provincia de Tucumán. Tenían familiares militantes de una organización de la izquierda armada y habían colaborado con la Comisión de Familiares de Presos Políticos de su provincia. Movidos por el clima de terror y represión que se instaló en Tucumán desde 1974, comenzaron a buscar formas de salir, primero de la provincia y a partir de 1975 del país.

En ese momento difícil consideraron huir a Perú por vía terrestre, pero el golpe en ese país en agosto de 1975 los desalentó. Las "caídas de casas", asesinatos y desapariciones de amigos cercanos los obligaron a escapar de su provincia en 1976 y radicarse por un tiempo en Córdoba junto a un matrimonio de amigos que también buscaban salir del país por miedo a ser víctimas de la represión: Nélida Sosa y Alfredo Forti, a quienes ya nos hemos referido. Gracias al apoyo del religioso Arturo Paoli, los dos hombres, ambos médicos, lograron un contrato de trabajo en Venezuela y viajaron allí con el plan de hacer los arreglos legales para la radicación y viaje de sus familias.

Por su parte, B.A. regresó para ayudar a las dos familias a organizar la salida de Argentina. Nélida Sosa y cinco de sus hijos debían salir primero, pero fueron secuestrados arriba del avión. B.A. y L.V junto con sus seis niños debieron descartar su plan de escapar por Ezeiza. Una vez 
Mario Ayala

Rutas de exilio entre Argentina y Venezuela, 1974-1980: circulaciones, tránsitos y re-exilios en el contexto regional

superado el pánico inicial, decidieron salir como turistas por vía fluvial hacia Montevideo -abordando de forma precipitada "el último Vapor de la carrera" para reducir tiempos de controles- y desde allí tomaron un vuelo hasta Rio Grande Do Sul, luego otro a Rio de Janeiro y un último vuelo hasta Caracas, todo con la intención de despistar las posibles sospechas de los represores en Argentina y países limítrofes (B.H., 2008).

Finalmente, debemos señalar que, si bien las rutas de exilio indirecto a través de Brasil o Uruguay fueron las más observadas entre los perseguidos que llegaron a Venezuela durante los primeros cuatro años de la dictadura militar, también encontramos una ruta que fue poco transitada debido a su extremo peligro: viajar por vías terrestres hasta Venezuela atravesando Argentina, Chile, Perú, Ecuador y Colombia hasta la frontera colombo-venezolana de Trujillo. Este fue el caso de L.M. (L.M., 2010), un ex estudiante universitario y activista "independiente de izquierda marxista" que hasta 1978 participó de una red clandestina de militantes del Partido Comunista Marxista Leninista (PCML) dedicada a ayudar a escapar a militantes perseguidos en peligro. A mediados de 1979 fueron secuestrados sus contactos y L.M. comenzó a ser buscado por la policía, lo que inició su desplazamiento por casas de familiares hasta que la situación se hizo insostenible y decidió salir del país con la ayuda de A.R. (A.R., 2009), un amigo militante del PCML que había escapado a Caracas vía Brasil en 1977 y que en ese momento colaboraba en el Programa Venezolano Pro Refugiados Latinoamericanos (Pro-Refugiados) ${ }^{13}$.

Según L.M., decidió escapar hacia Venezuela por vía terrestre junto a un compañero peruano del PCML por temor a ser detenidos, por falta de recursos, por no tener pasaportes y por no disponer de visas de ingreso. Ambos hicieron un viaje en ómnibus hasta Mendoza, luego por Chile hasta la frontera norte -donde fueron detenidos, torturados y luego expulsados por los carabineros de ese país- y desde allí hacia Perú, desde donde L.M. continuó viajando solo y donde estuvo cerca de ser detenido por la policía. Pasó por Quito y Bogotá, donde retiró la visa venezolana que le gestionó Pro-Refugiados desde Caracas, e ingresó a Venezuela por la frontera de Trujillo en noviembre de 1979 (L.M., 2010).

Por otra parte, entre los itinerarios de exilio indirecto posteriores al golpe de Estado encontramos casos de reubicaciones en el exilio desde países europeos. Se trató de tres personas que se trasladaron desde Europa hacia Venezuela por motivos políticos, laborales, por redes de amistad y cercanía cultural del país. Vale la pena detenerse brevemente en cada uno de ellos por su especificidad y por la riqueza de temas y problemas que

13 Pro-Refugiados funcionó entre 1978 y 1980 como un grupo de trabajo centrado en la solidaridad humanitaria con los refugiados latinoamericanos con sede en Caracas e integrado por activistas religiosos y laicos venezolanos y exiliados conosureños. Se recomienda consultar: (Ayala en Jensen y Lastra, 2014). 
dejan planteados. El primero fue el de Carmelo (Affatato, 2013), un obrero metalúrgico de nacionalidad italiana, delegado gremial de la Coordinadora Fabril de La Matanza. Después del golpe militar fue rescatado por el Consulado Italiano de Buenos Aires y enviado a Roma. Luego de unos meses de estadía en Italia y otros de trabajo en el sur de Alemania, decidió re-emigrar a Venezuela debido al extrañamiento cultural que vivía en Europa. Lo consiguió gracias a una oferta de trabajo gremial en la sede de la socialcristiana Central Latinoamericana de los Trabajadores (CLAT) de Caracas, donde vivió y trabajó hasta 1984.

El segundo caso fue el de Patrick (Rice, 2008), un sacerdote obrero y "villero" de origen irlandés, detenido-desaparecido en 1976 y luego expulsado a Inglaterra por la dictadura militar. Decidió radicarse en Caracas en 1979 para trabajar como religioso en la zona popular de Petare y, sobre todo, participar en acciones de denuncia de las dictaduras de la región y de solidaridad con sus víctimas: llegó a ser uno de los fundadores de la Federación Latinoamericana de Asociaciones de Familiares de DetenidosDesaparecidos (FEDEFAM). El tercero fue el caso de R.S. (R.S., 2011), ingeniero de nacionalidad argentina y ex preso político liberado, quien a fines de 1979 obtuvo autorización para salir a Francia bajo la protección del gobierno de este país. Unos meses después se trasladó de Francia a Venezuela en busca de un lugar con cercanía cultural y lingüística en donde ejercer su profesión, lo que logró con la ayuda de amigos ex militantes de la Juventud Peronista exiliados en la ciudad andina de Mérida.

Las rutas de exilio serial entre los que llegaron a Venezuela durante la última dictadura militar argentina representaron 11 casos (el $22 \%$ ), uno desde Bolivia y los restantes desde Perú. El primer ejemplo de itinerario de exilio serial fue el matrimonio de académicos de C.R y S.H. (S.H., 2010) relacionados con la agrupación Peronismo de Base, quienes se exiliaron en Bolivia a mediados de 1975. Habían sido cesanteados en las Universidades del Sur y del Comahue, y se les había iniciado una causa judicial "por subversión" en un juzgado de Bahía Blanca. Ante ese ambiente de violencia legal y clandestina que los ponía en peligro, la pareja decidió desplazarse primero a Buenos Aires y en julio de 1975 resolvió salir del país con un contrato de empleo para un programa de la ONU en Cochabamba. El hecho de contar con pasaportes de la ONU les habría dado confianza para residir en el país limítrofe, que se encontraba desde 1971 bajo una dictadura militar encabezada por el general Hugo Banzer. Sin embargo, después del golpe de Estado de marzo de 1976 en Argentina, decidieron re-exiliarse en Venezuela debido a la sensación de vulnerabilidad y falta de seguridades para residir en Bolivia, por un lado, y ante las oportunidades laborales que se les ofrecía en Maracaibo gracias a redes de académicos exiliados, por el otro. Así, el temor a un accionar represivo clandestino coordinado entre fuerzas de seguridad y militares de Argentina y Bolivia (la posibilidad de una extradición, secuestro o asesinato) los volvió a lanzar al exilio. Pudieron 
Mario Ayala

Rutas de exilio entre Argentina y Venezuela, 1974-1980: circulaciones, tránsitos y re-exilios en el

reubicarse en Venezuela gracias a un contrato de trabajo en La Universidad del Zulia, que les garantizó el acceso a una visa de trabajo y, por lo tanto, el ingreso al país (S.H., 2010) ${ }^{14}$.

Respecto de los itinerarios seriales que llegaron a Venezuela después de un primer exilio en Perú, se trató un grupo de exiliados que había comenzado a establecerse en ese país desde 1974 que decidieron re-exiliarse después de 1976, cuando la dictadura peruana entró en una etapa derechista y represiva con las izquierdas y los refugiados políticos en su territorio. El análisis de estas trayectorias y de la bibliografía especializada (Jensen 2004; 2007) indica que Perú se convirtió en un importante destino y lugar de exilio en el período represivo previo al golpe militar argentino de 1976, por la facilidad para acceder a la visa de ingreso, el bajo costo del viaje, la preexistencia de vínculos familiares o políticos y porque fue evaluado como sitio seguro y cercano para una estadía transitoria fuera de la Argentina y, en algunos casos, como un lugar de retaguardia de la lucha política.

La situación de inseguridad de los exiliados argentinos en Perú se incrementó desde agosto de 1975, tras el desplazamiento de Juan Velasco Alvarado (1968-1975) del gobierno militar y su reemplazo por el general Francisco Morales Bermúdez (1975-1980). A partir de entonces se generalizaron la vigilancia policial, por un lado, y las restricciones para permanecer, residir y trabajar de forma legal en el país, por el otro. En unos pocos meses esta política de vigilancia, hostigamiento y restricciones migratorias dejó en situación de ilegalidad a quienes permanecían en este país con visas de estancia corta (visas de turista y transeúnte), situación legal y represiva que comprometía a un número significativo de los argentinos exiliados.

Estos cambios respecto de los refugiados políticos formaron parte de un proceso de derechización creciente de la dictadura militar peruana bajo el control de Morales Bermúdez, que abandonó el perfil reformistadesarrollista que había impulsado Velasco Alvarado, ingresando en una segunda fase que fue conservadora en lo económico y lo político, reprimiendo y persiguiendo a la izquierda y a los sindicatos que protestaban por la crisis económica y demandaban la apertura democrática. ${ }^{15}$ Mientras que en el ámbito regional, la nueva fase de la dictadura peruana inició en una etapa de alineamiento con la dictadura argentina y su Doctrina de Seguridad Nacional centrada en el amplio y genérico enemigo interno "subversivo" (Slatman, 2008).

14 En Venezuela ambos formaron parte del grupo de académicos que trabajaron en la Universidad del Zulia, junto a Alfredo Pucciarelli y José Sazbón. Entre 1976 y 1979 residieron en Maracaibo y luego se trasladaron a México.

15 Para el contexto de emergencia y desarrollo de los gobiernos militares peruanos de la década de 19601970 se consultaron los siguientes trabajos: (Angell, 1984; Pease, 1979). 
Un ejemplo claro de este proceso fue que partir de 1976 Perú deportó a líderes opositores y militares peruanos hacia la Argentina ${ }^{16}$ y permitió que grupos de tareas de las Fuerzas Armadas Argentinas (FF. AA) operaran dentro de su territorio para reprimir exiliados en coordinación con sus fuerzas policiales y militares (Pierini \& Jauretche, 1999). Esto sucedió por lo menos desde abril de 1977, cuando un comando de militares argentinos secuestró y desapareció en Lima al ex montonero Carlos Maguid y lo trasladó a un centro clandestino de detención y tortura en Argentina ${ }^{17}$. Esta desaparición forzada perpetrada en plena capital peruana provocó una profunda conmoción en la colonia de exiliados argentinos. El hecho apareció mencionado insistentemente en nuestras entrevistas como un motivo clave para tomar la decisión de abandonar Perú en busca de países más seguros para transitar el exilio.

De la gran variedad de ejemplos que podríamos presentar, tres casos ilustran el espectro de las experiencias que llevaron a exilios seriales de Perú a Venezuela. El primero es el de Alicia Fondevila -obrera y dirigente de la Federación Gráfica Bonaerense- y dos de sus compañeras quienes huyeron de Buenos Aires con destino Lima a fines de julio de 1975 después de ser amenazas por la Triple A:

Mientras tanto ocurrían cosas. Lo derrocaron al presidente Velasco Alvarado, quien era uno de los pilares con que contábamos nosotros para estar en Lima. Eso ocurrió al mes de haber llegado y a partir de eso cambia el panorama. Allí es donde cambia el rumbo de la revolución peruana. Lo echan a Velasco y queda Morales Bermúdez, de la corriente de derecha que va a reventar toda América Latina. Casi al año la situación en Perú empieza a ponerse políticamente muy fea porque funcionaba la coordinación entre las Fuerzas Armadas de toda América Latina. En Lima secuestraron y mataron a Carlos Maguid, se decía que era uno de los que había integrado el comando que mató a Aramburu. [A partir de estos hechos] Empezaron a detener a casi todo el mundo. Luego los van largando como refugiados. A [Raimundo] Ongaro [líder de la FGB], que estaba en una reunión en Europa, le aconsejamos que no volviera. [...]En ese momento se había pensado que fuéramos todos para Europa. Como nosotras no queríamos ir, el grupo se disuelve. Susana Buconic y Rodolfo Savastano se fueron para Francia, Haydee se volvió a la Argentina y para nosotras, a través de Carlos Custer, la Central Latinoamericana de Trabajadores (CLAT) hizo las gestiones para salir a Venezuela (Fondevila, citada por: Moran, 2014: 25).

El segundo ejemplo es la trayectoria de Raúl Martin, en el que las causas del exilio serial fueron una combinación de las crecientes restricciones y controles de la policía peruana con los problemas laborales y de continuidad de estudios, escenario ante el cual decidió reiniciar gestiones para ingresar

16 Véase por ejemplo los testimonios de víctimas de esta operación de coordinación represiva PerúArgentina en: Poder Judicial de la Nación: 01-12-2012, p. 61.

17 Unos años más tarde, en 1980, en el marco de la contraofensiva montonera, un grupo de represores argentinos secuestraron y desaparecieron a otros tres argentinos en una acción represiva extraterritorial que comenzó en Lima y terminó en Madrid (Pierini \& Jauretche, 1999). 
Mario Ayala

Rutas de exilio entre Argentina y Venezuela, 1974-1980: circulaciones, tránsitos y re-exilios en el 36 contexto regional

a Venezuela, que ya había intentado sin suerte en 1975. De acuerdo con Raúl en aquel momento percibía que en Venezuela tendría mejores condiciones de seguridad y de acceso a oportunidades de empleo y estudios, debido a la situación económica del país y a la existencia de redes familiares. Contactos familiares lograron que le otorgaran una visa de ingreso a Venezuela. Llegó a Caracas el 15 de noviembre de 1976, un día después del vencimiento de su visa de estadía en Perú (Martin, 2011).

También hubo casos de exiliados argentinos que fueron obligados a abandonar Perú en plazos de semanas por no renovación de visas y/o por razones de "seguridad nacional", con la amenaza de ser deportados a sus países de origen si no conseguían ser aceptados por terceros Estados. Este fue el del académico y militante democristiano M.P. (M.P., 2011), ex preso opcionado que llegó a Lima en diciembre 1975 con el apoyo de las redes regionales democristianas. M.P. trabajó como profesor en la Universidad Católica del Perú hasta que en agosto de 1977 fue requerido por la Policía de Inteligencia Peruana (PIP) e interrogado por sus antecedentes políticos. Tras el interrogatorio le informaron que tenía un mes para presentar pruebas de haber sido sobreseído por las autoridades argentinas y de formar parte del Partido Cristiano Popular. Cumplido el plazo, M.P. se presentó en la PIP sin haber conseguido los certificados solicitados y a continuación fue interrogado durante doce horas. Al día siguiente lo citaron nuevamente para comunicarle que sería deportado y que debería pasar las noches bajo guardia en una comisaría hasta conseguir un país que lo recibiera. El gobierno militar peruano le dio cinco días para salir del país, con la posibilidad de ser deportado a la Argentina. Pero logró salir a Caracas en 15 días, gracias a contactos con el partido venezolano socialcristiano COPEI, el cual gestionó ante el gobierno venezolano para le entregaran pasaporte de emergencia y visa de ingreso a Venezuela en su Consulado de Lima.

\section{Balance final}

El objetivo de este artículo fue reconstruir las rutas de exilios de los exiliados que se instalaron en Venezuela entre 1974 y 1980, apoyado en testimonios de trayectorias personales, documentación diplomática venezolana y bibliografía especializada. En base al análisis documental delimitamos tres tipos de rutas de exilio: (directas, indirectas y seriales), buscando detectar los factores que determinaron estos itinerarios y desplazamientos forzados por razones políticas.

El análisis de las 28 trayectorias quellegaron a Venezuela durante el tercer gobierno peronista mostró que las rutas de exilio directas representaron el $68 \%$ del total de casos; las rutas de exilio indirectas (con situaciones de tránsitos en países de la región), el 29 \%; y las rutas de exilio serial (desde 
Perú), el 3\%. Los factores que incidieron en la configuración de estas rutas fueron: a) la política represiva legal, ilegal y clandestina del Estado expulsor que dejó márgenes de maniobra para acceso a documentación internacional y salidas por la vía aérea; b) la percepción de los actores de que era una salida temporaria, lo que los llevó a elegir países cercanos geográfica y culturalmente; c) las condiciones de recepción, protección y posibilidades de continuar con su actividad política que brindaban (o no) otros países de la región; d) la política venezolana restrictiva de asilos e ingresos de perseguidos políticos argentinos. Estos factores ayudan a explicar por qué en el período previo a la dictadura militar Perú fue utilizado como un territorio desde donde trasladarse a otros países que demandaban largas gestiones para acceder a visas, como Venezuela, y también como lugar de primer exilio. Perú fue un destino prioritario por las ventajas comparativas que presentaba frente a otros países.

En relación con las 44 trayectorias de exiliados que llegaron a Venezuela durante la dictadura militar argentina entre 1976 y fines de 1979 e inicios de 1980, se observó una importante reducción de las rutas de exilio directas (del 68 al 40 \%), un incremento de las rutas de exilio indirectas (del 29 al 36 $\%$, esta vez con tránsitos en Brasil y en menor medida en Uruguay y países europeos), y un importante incremento de las rutas de exilio serial (del 3 a $22 \%$, centralmente desde Perú). Los factores generales que incidieron en la configuración de estas rutas de exilio fueron por lo menos tres. El primero fue el cambio cualitativo y cuantitativo de la escala y amplitud del accionar represivo a partir del golpe de Estado de marzo de 1976, mediante la suspensión de las garantías constitucionales y la aplicación de un plan nacional -y también extraterritorial- clandestino, centrado en las desapariciones forzadas para eliminar "subversivos".

Esta política represiva de la dictadura militar redujo las posibilidades de sostener la clandestinidad, las salidas por el aeropuerto internacional, el acceso a documentación internacional y la posibilidad de refugiarse en países de la región bajo gobiernos militares, situación que se comenzó a relajarse a partir de 1979 cuando se inicia una oleada de exilios. El segundo factor condicionante continúo siendo la restricción del derecho de asilo y de entrega de visas por la Cancillería venezolana en Buenos Aires para perseguidos y presos políticos de las izquierdas de la época; política de asilo anticomunista, que se mantuvo a pesar de la intensificación de la violencia represiva en la Argentina. En los casos en que se otorgaron de visas y pasaportes de emergencia, se impuso la condición de que debían usarse desde terceros países o bien serían entregados en países limítrofes y de la región.

El tercer factor fueron los cambios en la situación interna de dos dictaduras de la región: la dictadura peruana ingresó en una fase derechista y represiva desde mediados de 1975, que abandonó su política de protección 
Mario Ayala

Rutas de exilio entre Argentina y Venezuela, 1974-1980: circulaciones, tránsitos y re-exilios en el

y acogida de perseguidos de la región, obligando a re-exiliarse en terceros países a buena parte de la colonia de exiliados argentinos. Mientras tanto, la dictadura de Brasil, inició un proceso de distensión política que implicó cierta tolerancia al movimiento y permanencia transitoria de exiliados de la región que adoptarán el estatuto de refugiado del ACNUR, cuya oficina funcionaba de hecho en Río de Janeiro desde 1977.

La hipótesis general a la que arribamos es que tanto las vías a través de las cuales los perseguidos y presos políticos salieron de Argentina al exilio entre 1974 y 1983, como los itinerarios o rutas de exilio variaron en función de las estrategias de los sujetos exílicos en interacción con los contextos represivos del país expulsor, de la política de asilo y recepción de los países ante los cuales solicitaron protección y de las condiciones políticas regionales e internacionales en que se desplegaron los viajes forzados.

Desde una perspectiva más amplia esta investigación presenta un debate sobre los factores que condicionan los itinerarios y desplazamientos de exiliados, mostrando que fueron consecuencia de las modalidades represivas del país expulsor y de la política de recepción restrictiva en asilo e inmigración que junto a las condiciones políticas regionales explican las vías de escape y las rutas de exilio. En definitiva, aunque el análisis se apoya en la experiencia de las rutas de exiliados argentinos entre su país de origen y Venezuela, el artículo propone una discusión más amplia sobre las lógicas políticas y tramas represivas regionales que condicionan estos desplazamientos forzados y dan sentido a las circulaciones, tránsitos, reubicaciones y re-exilios en el escenario de la última ola represiva en el Cono Sur de América Latina.

\section{Referencias Bibliográficas}

ANGELL, Alan. 1984. El gobierno militar peruano de 1968 a 1980: el fracaso de la revolución desde arriba. En: Foro Internacional, $\mathrm{N}^{\circ} 25$.

AYALA, Mario. 2017a. "La experiencia del Comité Venezolano de Solidaridad con el Pueblo Argentino (Caracas-Mérida, 1976-1983)” En: Opción, Revista de Ciencias Humanas y Sociales, Vol. 33, Núm. 83, pp. 99-136

AYALA, Mario. 2014. Los exiliados argentinos en Venezuela. Solidaridad, denuncia y construcción de redes regionales de Derechos Humanos. En: JENSEN, Silvina y LASTRA, Soledad (edits.) Exilios: militancia y represión. Nuevas fuentes, nuevos abordajes de los destierros de la Argentina en los años setenta. EDULP. La Plata, Argentina. 
AYALA, Mario. 2017b. “Antecedentes históricos e historiografía de los exilios políticos del Cono Sur de América Latina” En: Con-temporánea. Toda la historia en el presente, $1^{\mathrm{a}}$ época, volumen 4 , Núm. 7 enero-junio. pp. 124-152.

AYALA, Mario. 2017c. Exiliados argentinos en Venezuela (1974-1983). (Tesis de doctorado) Facultad de Filosofía y Letras de la Universidad de Buenos Aires. Buenos Aires, Argentina.

FERNÁNDEZ, Jorge Christian. 2011. Anclaos en Brasil: a presença argentina no Rio Grande do Sul (1966 - 1989). (Tesis doctoral) Programa de PósGraduação em Historia da Universidade Federal do Rio Grande do Sul. Rio Grande Dos Sul.

FRANCO, Marina. 2006. Los emigrados políticos argentinos en Francia (19731983). (Tesis doctoral) Universidad de París 7, Universidad de Buenos Aires. Buenos Aires, Argentina.

FRANCO, Marina. 2008. El Exilio: argentinos en Francia durante la dictadura. Siglo XXI. Buenos Aires, Argentina.

FRANCO, Marina. 2012. Un enemigo para la nación. Orden, violencia y "subversión", 1973-1976. Fondo de Cultura Económica. Buenos Aires, Argentina.

JENSEN, Silvina .2004. Suspendidos de la Historia/Exiliados de la Memoria. El caso de los argentinos desterrados en Cataluña (1976- ...) (Tesis doctoral), Departament d' Història Moderna i Contemporània, Facultat de Filosofía i Lletres, Universitat Autònoma de Barcelona. Barcelona, España.

JENSEN, Silvina .2015. "Sobre La política del destierro y el exilio en América Latina de Mario Sznadjer y Luis Roniger. Hacia un enfoque sociopolítico, macrohistórico y teórico-analítico del problema” En: Historia, voces y memoria. No. 8, pp. 13-20

JENSEN, Silvina. 2007. La provincia flotante. Historia de los exiliados argentinos de la última dictadura militar en Cataluña (1976-2006). Fundació Casa Amèrica Catalunya. Barcelona, España.

MORAN, Micaëlla. 2014. Trayectorias en la industria gráfica: entre el sindicato y la vida personal. Facultad de Ciencias Económicas de la Universidad de Buenos Aires. Documento de Trabajo No 87. Buenos Aires, Argentina.

PARCERO, Daniel. 1985. La Argentina exiliada. Centro Editor de América Latina. Buenos Aires, Argentina. 
Mario Ayala

Rutas de exilio entre Argentina y Venezuela, 1974-1980: circulaciones, tránsitos y re-exilios en el 40 contexto regional

PEASE, Henry. 1979. "Perú actual: crisis política tras una década militar" En: Cuadernos Políticos, número 19, Editorial Era, enero-marzo. México DF., México.

PELLEGRINO, Adela. 1989. Historia de la inmigración en Venezuela siglos $X I X$ y XX (Vol. 1). Academia Nacional de Ciencias Económicas, Caracas, Venezuela.

PIERINI, Alicia; JAURETCHE, Ernesto. 1999. Guerra sucia en el Perú. En: Página 12. Disponible en línea. En: https://www.pagina12.com. ar/1999/99-02/99-02-07/pag10.htm. Fecha de consulta: 22/08/2019.

PODER JUDICIAL DE LA NACIÓN. 2012. Resolución Napuri y otros de Causa Videla por privación ilegítima de libertad, Causa No. 80392971. Buenos Aires, argentina.

SIMÕES FERNANDES, Ananda. 2014. "O controle da resistência e da solidariedade dos refugiados políticos no Brasil pela comunidade de segurança e informação da ditadura civil-militar brasileira” En: IV Jornadas Internacionais de Problemas Latino-Americanos. UNILAUNIOESTE, 27-29 de novembro. Foz do Iguaçu, Brasil.

SLATMAN, Melisa. 2008. "El accionar represivo extraterritorial de las Fuerzas Armadas Argentinas en el marco del Operativo Cóndor (1975-1980)" En: SLATMAN, Melisa, AYALA, Mario; KONDOLF, Cecilia comps. Los Movimientos Sociales en América Latina. Pasado, presentey perspectivas. Proyecto Editorial Gregorio Selser. Buenos Aires, Argentina.

SLATMAN, Melisa; SERRA PADROS, Enrique. 2014. Brasil y Argentina: modelos represivos y redes de coordinación durante el último ciclo de dictaduras del Cono Sur. Estudio en clave comparativa y transnacional. En: Jensen, Silvina y Lastra, Soledad (edits.). Exilios: militancia y represión. Nuevas fuentes, nuevos abordajes de los destierros de la Argentina en los años setenta. EDULP. La Plata, Argentina.

SZNAJDER, Mario y RONIGER, Luis. 2004. "De Argentina a Israel: escape y exilio" En: Yankelevich, Pablo (comp.). Represión y destierro: Itinerarios del exilio argentino. Ediciones Al Margen. La Plata, Argentina.

SZNAJDER, Mario; RONIGER, Luis. 2013. La política del destierro y el exilio en América Latina. Fondo de Cultura Económica. México DF., México.

VIZ QUADRAT, Samantha. 2007. "Exiliados argentinos en Brasil: una situación delicada" En: Yankelevich, Pablo y Jensen Silvina (comps.). Exilios. Destinos y experiencias bajo la dictadura militar. Libros del Zorzal. Buenos Aires, Argentina. 
YANKELEVICH, Pablo. 2008. "Dictadura y Exilio" En: Lida, Clara; Crespo, Horacio y Yankelevich, Pablo. Argentina, 1976. Estudios en torno al golpe de Estado. Fondo de Cultura Económica/El Colegio de México. Buenos Aires, Argentina.

YANKELEVICH, Pablo. 2010. Ráfagas de un exilio. Argentinos en México (1974-1983). Fondo de Cultura Económica/El Colegio de México. Buenos Aires, Argentina.

\section{Entrevistas citadas}

AFFATATO, C. 2013. Exilio argentino en Venezuela [In person]. Ramos Mejía, Argentina.

A. R. 2009. Exilio argentino en Venezuela [In person]. Caracas, Venezuela.

ACTIS, N. 2012. Exilio argentino en Venezuela [In person]. Buenos Aires, Argentina.

B.A. 2008. Exilio argentino en Venezuela [In person]. Buenos Aires, Argentina.

CANAL ENCUENTRO. 2015a. Encuentro con Argentores - Juan Carlos Gené, [Video]. Disponible en línea. En: http://www.encuentro.gov.ar/ sitios/encuentro/programas/ver?rec_id=108925. . Fecha de consulta: 12/03/2019.

CANAL ENCUENTRO. 2015b. "Somos Memoria-Norman Bridski" [Video]. Disponible en línea. En: http://www.encuentro.gov.ar/sitios/encuentro/ programas/ver?rec_id=108925. . Fecha de consulta: 12/03/2019.

CUBAS, R; QUIROGA, R. 2009. Exilio argentino en Venezuela [In person]. Buenos Aires, Argentina.

D.M. 2010. Exilio argentino en Venezuela [In person]. La Plata, Argentina.

DALEO, G. 2008. Exilio argentino en Venezuela [In person]. Buenos Aires, Argentina.

E, P. 2014. Exilio argentino en Venezuela [In person]. Buenos Aires, Argentina.

GASS, A. 2009. Exilio argentino en Venezuela [In person]. Buenos Aires, Argentina.

L, M. 2014. Exilio argentino en Venezuela [In person]. Buenos Aires, Argentina. 
Mario Ayala

Rutas de exilio entre Argentina y Venezuela, 1974-1980: circulaciones, tránsitos y re-exilios en el 42 contexto regional

L.M. 2010. Exilio argentino en Venezuela [In person]. Beccar, Argentina.

L.V. 2008. Exilio argentino en Venezuela [In person]. Buenos Aires, Argentina.

LUNA, J. 2008. Exilio argentino en Venezuela [In person]. Buenos Aires, Argentina.

M. B. 2008. Exilio argentino en Venezuela [In person]. Buenos Aires, Argentina.

M.P. 2011. Exilio argentino en Venezuela [In person]. Mérida, Venezuela.

MARTIN, M. 2011. Exilio argentino en Venezuela [In person]. Caracas, Venezuela.

NALDI, A. 2009. Exilio argentino en Venezuela [In person]. Ramos Mejia, Argentina.

R. F; M. T. Exilio argentino en Venezuela (2009). [In person]. Valencia, Venezuela.

R.Q. (2011). Exilio argentino en Venezuela [ In person]. Caracas, Venezuela.

R.S. 2011. Exilio argentino en Venezuela [ In person]. Mérida, Venezuela.

RICE, P. 2008. Exilio argentino en Venezuela [In person]. Buenos Aires, Argentina.

S.H. 2010. Exilio argentino en Venezuela [In person]. Buenos Aires, Argentina.

VILANOVA, V; TORRE, L. 2013. Exilio argentino en Venezuela [In person]. Buenos Aires, Argentina.

VILANOVA, V; TORRE, L. 2014. Exilio argentino en Venezuela [In person]. Buenos Aires, Argentina.

W. R. 2014. Exilio argentino en Venezuela [In person]. Buenos Aires, Argentina. 

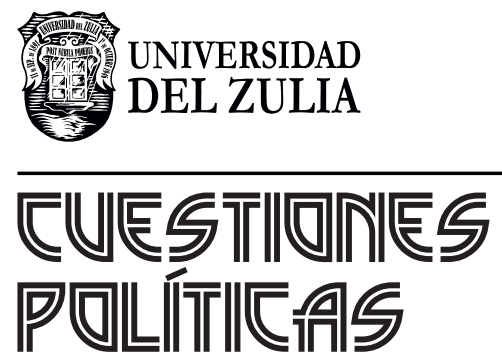

Vol. $37 \mathrm{~N}^{\circ} 64$

Esta revista fue editada en formato digital y publicada en junio de 2020, por el Fondo Editorial Serbiluz, Universidad del Zulia. Maracaibo-Venezuela 